\title{
Empirically derived maximal acceptable wait time for surgery to treat adolescent idiopathic scoliosis
}

\author{
Henry Ahn MD, Hans Kreder MD MPH, Nizar Mahomed MD ScD MPH, Dorcas Beaton PhD, \\ James G. Wright MD MPH
}

See related research article by Wright and colleagues at www.cmaj.ca/cgi/doi/10.1503/cmaj.101530.

\section{Abstract \\ Background: Prioritizing patients using empiri- cally derived access targets can help to ensure high-quality care. Adolescent scoliosis can worsen while patients wait for treatment, increasing the risk of adverse events. Our objective was to determine an empirically derived access target for scoliosis surgery and to compare this with consensus-based targets}

Methods: Two-hundred sixteen sequential patients receiving surgery for adolescent idiopathic scoliosis were included in the study. The main outcome was need for additional surgery. Logistic regression modeling was used to evaluate the relation between surgical wait times and adverse events and $\chi^{2}$ analysis was used as the primary analysis for the main outcome.

Results: Of the 88 patients who waited longer than six months for surgery, $13(14.8 \%)$ needed additional surgery due to progression of curvature versus $1.6 \%$ ( 2 of 128 patients) who waited less than six months for surgery $\left(\chi^{2}\right.$ analysis, $\left.p=0.0001\right)$. Patients who waited longer than six months for surgery had greater progression of curvature, longer surg- eries and longer stays in hospital. These patients also had less surgical correction than patients who waited less than six months for surgery (Wilcoxon-Mann-Whitney test, $p=$ 0.011 ). All patients requiring additional surgeries waited longer than three months for their initial surgery. A receiver-operator characteristic curve also suggested a three-month wait as an access target. The adjusted odds ratio for an adverse event for each additional 90 days of waiting from time of consent was 1.81 (95\% confidence interval 1.34-2.44). The adjusted odds ratio increased with skeletal immaturity and with the size of the spinal curvature at the time of consent.

Interpretation: A prolonged wait for surgery increased the risk of additional surgical procedures and other adverse events. An empirically derived access target of three months for surgery to treat adolescent idiopathic scoliosis could potentially eliminate the need for additional surgery by reducing progression of curvature. This is a shorter access target than the six months determined by expert consensus.
A dolescent idiopathic scoliosis effects just over $2 \%$ of females aged $12-14{\text { years. }{ }^{1-3}}^{-3}$ Although only $10 \%$ of patients require surgery, spinal instrumentation and fusion for adolescent idiopathic scoliosis is the most common procedure done in pediatric orthopaedics. ${ }^{4}$ Patients who wait too long for scoliosis surgery may require additional surgery such as anterior release to achieve satisfactory correction of the spinal curvature. These patients may also need longer surgeries and may be at increased risk of complications such as increased blood loss, neurologic deficits or inadequate correction of the curvature..$^{5-14}$ Furthermore, as seen in other studies of wait times, patients and families can feel anxiety and prolonged suffering while waiting for treatment, which can negatively impact the quality of care. ${ }^{15-19}$ Programs such as the Canadian Pediatric Surgical Wait Times Project have deter- mined a maximal acceptable wait time for adolescent scoliosis through expert consensus (similar to how other surgical wait time targets have been determined). ${ }^{20}$ Surprisingly, there has been little or no attention given to developing evidence-based access targets or maximal acceptable wait times for most treatments. ${ }^{21}$ The purpose of this study was to determine the maximal acceptable wait time for surgical correction of adolescent idiopathic scoliosis using an empirically based approach to minimize the possibility of adverse events related to progression of curvature.

\section{Methods}

\section{Population}

We used a sequential retrospective cohort of all 216 (176 girls, 40 boys) patients with adolescent idiopathic scoliosis who received surgery at the
Competing interests: None declared.

This article has been peer reviewed.

Correspondence to:

Dr. Henry Ahn, ahnh@smh.ca

CMAJ 2011. DOI:10.1503 /cmaj.101511 
Hospital for Sick Children in Toronto, Ontario (November 1997 to August 2005). Patients were identified using the Canadian Institute for Health Information Discharge Abstract Database and the hospital's registry of surgical procedures. Patients were included in the cohort if they had received a diagnosis of adolescent idiopathic scoliosis and if they were 11-17 years of age. Patients with neuromuscular, congenital, syndromic, juvenile or infantile idiopathic scoliosis were excluded. Approval was obtained from the Research Ethics Board before the beginning of the study.

Patients received segmental spinal fixation posteriorly with hooks, with or without pedicle screws, or anteriorly with a screw and rod construct (Universal Spine System, Synthes, West Chester, Pennsylvania, and Moss Miami, Depuy Spine, Warsaw, Indiana). Surgeries were done by four spinal surgeons using a standardized technique. All patients had curvatures with a Cobb angle measurement of at least $40^{\circ}$. The Cobb angle measures the angle in degrees between the top and bottom vertebrae in a spinal curvature on an anteroposterior radiograph of the spine. During the study period, curvatures with a Cobb angle of $40^{\circ}-70^{\circ}$ received either a posterior or anterior approach based on the pattern of the curvature; curvatures with a Cobb angle of $70^{\circ}-90^{\circ}$ received surgical correction in two stages - an anterior release, followed by a posterior approach one to two weeks later; curvatures greater than $90^{\circ}$ were similarly staged, but halofemoral traction with weights was applied during the two-week interval between procedures.

The surgical wait period, defined by the Ontario Ministry of Health as the interval between the day that both the surgeon and the patient agreed to surgical treatment and the day of surgery, ${ }^{22}$ was determined from the clinic and operative records. When the surgery was staged, the wait time was calculated relative to the first operation.

All patients had three-foot standing anteroposterior lateral radiographs taken just before the decision was made to proceed with surgery. Another set of radiographs was taken immediately before surgery. After surgery, a three-foot standing anteroposterior lateral radiograph was taken to assess correction of the curvature. Measurements were taken from the radiographs without chart abstraction.

The main outcome of the study was the need for additional surgery. This need was assessed

Table 1: Baseline characteristics and surgical data for the overall study population and the two surgical wait-time groups

\begin{tabular}{|c|c|c|c|c|}
\hline Characteristic & $\begin{array}{l}\text { Overall group } \\
\quad n=216\end{array}$ & $\begin{array}{c}<6 \text { months surgical } \\
\text { wait time } \\
n=128\end{array}$ & $\begin{array}{l}\geq 6 \text { months surgical } \\
\text { wait time } \\
n=88\end{array}$ & $p$ value \\
\hline Sex, no. (\%) & & & & $0.92 *$ \\
\hline Female & $176(81.5)$ & $104(81.2)$ & $72(81.8)$ & \\
\hline Male & $40(18.5)$ & $24(18.8)$ & $16(18.2)$ & \\
\hline Median age at first consultation, yr (IQR) & $13.2(12.2-14.5)$ & $13.5(12.4-14.6)$ & $13.1(11.8-14.4)$ & $0.98 t$ \\
\hline Median age of menarche, yr (IQR) & $12(12-13)$ & $12(12-13)$ & $12(12-13)$ & $0.66 t$ \\
\hline Median wait time for consultation, d (IQR) & $75(47-111)$ & $81(47-109)$ & $66(47-114)$ & $0.19+$ \\
\hline $\begin{array}{l}\text { Median maximal Cobb angle at first consultation, } \\
\text { degrees (IQR) }\end{array}$ & $55(46-62)$ & $54(46-62)$ & $55(47-72)$ & $0.13+$ \\
\hline Median wait time for surgery, d (IQR) & $149(92-228)$ & $103(69-142)$ & $247(217-308)$ & \\
\hline Median age of patients at surgery, yr (IQR) & $14.5(13.4-15.9)$ & $14.3(13.3-15.8)$ & $14.7(13.4-16.1)$ & $0.98 t$ \\
\hline $\begin{array}{l}\text { Median Risser score when appointment for surgery was } \\
\text { made (IQR) }\end{array}$ & $2(0-3)$ & $2(0-3)$ & $2(0-3)$ & $0.18+$ \\
\hline $\begin{array}{l}\text { Median maximal Cobb angle when appointment for } \\
\text { surgery was made, degrees (IQR) }\end{array}$ & $60(53-65)$ & $58(52-65)$ & $60(54-66)$ & $0.79+$ \\
\hline $\begin{array}{l}\text { Median maximal Cobb angle at time of surgery, } \\
\text { degrees (IQR) }\end{array}$ & $63(55-70)$ & $60(53-67)$ & $68(57-78)$ & $0.07 \dagger$ \\
\hline $\begin{array}{l}\text { Median progression of curvature between time when } \\
\text { appointment for surgery was made and time of surgery, } \\
\text { degrees (IQR) }\end{array}$ & $3(0-10)$ & $1(0-5)$ & $9(2-15)$ & $<0.001 \dagger$ \\
\hline Median BMI (IQR) & $20.5(18-21.6)$ & $19.8(17.3-21.8)$ & $20.6(18.0-21.6)$ & $0.72 t$ \\
\hline
\end{tabular}


using a comparison between the initial plan made when surgery was mutually agreed to and the surgery the patient actually received. The secondary outcomes were the following adverse events: more then $10^{\circ}$ of progression of curvature $^{23}$ (defined as the difference between the Cobb angles in the radiograph taken at the time surgery was scheduled and the radiograph taken just before surgery), less than $50 \%$ correction of the curvature (defined as the percent improvement in the Cobb angle from the postoperative radiograph and the radiograph taken just before surgery), the need for a blood transfusion, prolonged surgery (defined as the highest 10th percentile in duration between the beginning and the end of surgery, excluding anesthesia time) and perioperative neurologic injury.

\section{Statistical analysis}

For the primary analysis of need for additional surgery, we used a two-tailed $\chi^{2}$ test and a $p$ level of 0.05 . For the purpose of our statistical analyses, we used six months as the hypothetical maximal acceptable wait time. ${ }^{20}$ This hypothetical maximum was determined by a group of experts, not involved with this study, as part of a Canadian Pediatric Wait Times Project. ${ }^{20}$ Sample-size calculation showed that 75 patients were needed in each group, using an $\alpha$ of 0.05 and a $\beta$ of 0.80 to detect a $10 \%$ difference in rate of additional surgery between the two groups.

A logistic regression model was used to evaluate the relation between surgical wait times (independent continuous variable) and any adverse events as defined previously (outcome). We controlled for the following potential confounders: the size of the curvature at the time consent for surgery was given, the Risser scale (a radiographic marker of skeletal maturity based on the degree of lateral excursion of the iliac apophysis and scored from 0 to 5, with 5 representing full maturity) and the patient's age. ${ }^{8-12,24,25}$ The Hosmer-Lemeshow goodness-of-fit test confirmed a good model fit by failing to reject the null hypothesis with an $\alpha$ of $0.05(p=0.10)$.

The odds ratio (OR) for an adverse event was converted into a probability using the following equation: probability $=\mathrm{OR} /(1+\mathrm{OR})$.

Table 2: Clinical and surgical outcomes in the overall study population and in the two surgical wait-time groups

\begin{tabular}{|c|c|c|c|c|}
\hline \multirow[b]{2}{*}{ Characteristic } & \multicolumn{3}{|c|}{ No. $(\%) *$} & \multirow[b]{2}{*}{$p$ value } \\
\hline & $\begin{array}{l}\text { Overall group } \\
\quad n=216\end{array}$ & $\begin{array}{l}<6 \text { months } \\
\text { surgical wait time } \\
\quad n=128\end{array}$ & $\begin{array}{l}\geq 6 \text { months } \\
\text { surgical wait time } \\
\quad n=88\end{array}$ & \\
\hline $\begin{array}{l}\text { Patients needing additional surgery due to progression of } \\
\text { curvature }\end{array}$ & $15(6.9)$ & $2(1.6)$ & $13(14.7)$ & $0.002 \dagger$ \\
\hline Patients with any adverse events & $127(58.8)$ & $62(48.4)$ & $65(73.9)$ & $0.002+$ \\
\hline $\begin{array}{l}\text { Patients whose curvature progressed by }>10^{\circ} \text { while } \\
\text { waiting for surgery }\end{array}$ & $54(25.0)$ & $17(13.3)$ & $37(42.0)$ & $0.001+$ \\
\hline Median no. of levels fused & $11(9-12)$ & $10(9-12)$ & $11(10-13)$ & $0.003 \ddagger$ \\
\hline Surgical approach & & & & $0.013+$ \\
\hline Anterior and posterior & $41(19.0)$ & $20(15.6)$ & $21(23.9)$ & \\
\hline Anterior only & $15(6.9)$ & $8(6.3)$ & $7(7.9)$ & \\
\hline Posterior only & $160(74.1)$ & $100(78.1)$ & $60(68.2)$ & \\
\hline Patients needing thoracoplasty & $49(22.7)$ & $29(22.7)$ & $20(22.7)$ & $0.990 t$ \\
\hline Median blood loss, mL (IQR) & $1000(700-1500)$ & $1001(700-1500)$ & $1000(700-1500)$ & $0.410 \ddagger$ \\
\hline Patients needing blood transfusion & $20(9.3)$ & $14(10.9)$ & $6(6.8)$ & $0.300 t$ \\
\hline Median surgical time, $\min (\mathrm{IQR})$ & $462(390-540)$ & $432(375-535)$ & $480(420-570)$ & $0.0011 \ddagger$ \\
\hline Patients with prolonged surgical time§ & $24(11)$ & $10(7.8)$ & $14(15.9)$ & $0.06+$ \\
\hline Patients with somatosensory-evoked potential changes & $15(6.94)$ & $6(4.7)$ & $9(10.2)$ & $0.11+$ \\
\hline Median length of stay in hospital after surgery, $d$ (IQR) & $8(6-10)$ & $7(6-8)$ & $9(7-11)$ & $0.0302 \ddagger$ \\
\hline Median size of curve after surgery, degrees (IQR) & $23(18-30)$ & $22(18-28)$ & $27(19-33)$ & $0.003 \ddagger$ \\
\hline Patients with $<50 \%$ correction of curvature & $63(29.2)$ & $29(22.7)$ & $34(38.6)$ & $0.011 \dagger$ \\
\hline \multicolumn{5}{|c|}{$\begin{array}{l}\text { Note: IQR }=\text { interquartile range. } \\
\text { *Unless otherwise indicated. } \\
+\chi^{2} \text { test. } \\
\text { fWilcoxon-Mann-Whitney test. } \\
\text { §Prolonged surgical wait time was defined as the highest } 10 \text { th percentile in duration between the beginning and the end of surgery, excluding anesthesia time. }\end{array}$} \\
\hline
\end{tabular}




\section{Results}

From November 1997 to August 2005, 216 se quential patients (176 girls, 40 boys) received surgery for adolescent idiopathic scoliosis. Patients who waited longer than or less than six months had comparable baseline characteristics (Table 1). Furthermore, regression revealed no relationship between wait time and baseline characteristics, including age, sex or the size or Risser score of the curvature.

\section{Primary outcome}

Additional surgery was necessary for 15 (6.9\%) of the 216 patients (Table 2). Of the 88 patients who waited six months or longer for their initial surgery, $13(14.7 \%)$ required additional surgery compared with 2 of 128 patients $(1.6 \%)$ who had waited less than six months for their initial surgeries $\left(\chi^{2}\right.$ analysis, $p=0.0002$ ). The two patients who had waited less than six months and who required additional surgery both had curvatures measuring less than $70^{\circ}$ at the time that their first surgeries were scheduled; one of these patients waited 97 days, and the other patient waited 180 days. Wait times for the initial procedures for the 13 patients requiring additional surgery who waited longer than six months were between 204 and 544 days.

For the 15 patients requiring additional surgery, $13(86.7 \%)$ were initially scheduled for a posterior-only approach at the time of surgical consent. Due to the progression of these patients' spinal curvatures to greater than $70^{\circ}$ while waiting, both anterior and posterior approaches were done at the time of surgery. Two of the 15 patients requiring additional surgery $(13.3 \%)$ had curvatures that were between $70^{\circ}$ and $90^{\circ}$ at the time the decision was made to proceed with surgery, but they received traction after the initial anterior release because their curvatures had progressed to more than $90^{\circ}$.

\section{Secondary outcomes}

The odds of any adverse event for those waiting longer than six months (defined as 182 days or more) was 3.32 (95\% CI 1.8-6.2) (Table 3). Confounders were the size $(p=0.007)$ and Risser score $(p=0.007)$ of the curvature at the time that consent was given and the surgery was scheduled (Table 3 ). Larger curvatures and lower Risser scores at this time increased the odds of an adverse event occurring (corresponding ORs of 1.04 [95\% CI 1.0111.072] and 0.76 [95\% CI 0.64-0.91]) (Table 3). The probability that an adverse event would occur was dominated by long waits or large curvatures (e.g. $100^{\circ}$ ). The effect of skeletal immaturity at the time of consent was more moderate.

A receiver-operator characteristic (ROC) curve was used to graphically assess the impact of various access targets as cutoffs, increasing incrementally from 1 to 365 days, on the potential prevention of adverse events among patients who truly did have an adverse event (true positives) versus the prevention of adverse events in patients who did not have an adverse event (false positives) (Figure 1). On the ROC curve, two operating points are marked: the left point, based on visual appearance, was closest to being a potential inflection point and represents a four-month access target (true-positive rate $=76 \%$, false-positive rate $=46 \%$ ); the right point represents a three-month access target (truepositive rate $=84 \%$, false-positive rate $=64 \%$ ). The three-month cutoff had increased true-positive and false-positive rates compared with the four-month cutoff. The three-month access target was the shortest wait time (97 days) for which additional surgery was necessary due to progression of curvature. The adjusted OR for any adverse event occurring at this

\begin{tabular}{|c|c|c|c|c|}
\hline Variable & $\begin{array}{l}\text { Unadjusted OR } \\
(95 \% \mathrm{Cl})\end{array}$ & $p$ value & $\begin{array}{l}\text { Adjusted OR } \\
\quad(95 \% \mathrm{Cl})\end{array}$ & $p$ value \\
\hline $\begin{array}{l}\text { Wait time per additional } \\
90 \mathrm{~d}\end{array}$ & $1.73(1.30-2.30)$ & 0.0001 & $1.81(1.34-2.44)$ & 0.0001 \\
\hline $\begin{array}{l}\text { Risser scale per unit } \\
\text { change }\end{array}$ & $0.84(0.72-0.98)$ & 0.0305 & $0.76(0.64-0.91)$ & 0.007 \\
\hline $\begin{array}{l}\text { Size of curve when } \\
\text { surgery was scheduled per } \\
\text { degree in size }\end{array}$ & $1.04(1.01-1.07)$ & 0.005 & $1.04(1.01-1.07)$ & 0.007 \\
\hline $\begin{array}{l}\text { Age at time of consent } \\
\text { per year of age }\end{array}$ & $0.96(0.86-1.08)$ & 0.50 & $0.99(0.86-1.14)$ & 0.89 \\
\hline \multicolumn{5}{|c|}{$\begin{array}{l}\text { Note: } \mathrm{Cl}=\text { confidence interval, } \mathrm{OR}=\text { odds ratio. } \\
\text { *Adverse events included one or more of the following: surgery in addition to that planned at time of consent, curve } \\
\text { progression of more than } 10^{\circ} \text { while waiting for surgery, less than } 50 \% \text { correction of curve, need for a blood transfusion, } \\
\text { prolonged surgery and perioperative neurologic injury. }\end{array}$} \\
\hline
\end{tabular}


three-month mark and per additional 90 days of waiting was 1.81 (95\% CI 1.34-2.44).

\section{Interpretation}

Determining empirically derived maximal acceptable wait times provides important information for clinicians and the agencies that fund health care. In this study, we have shown that prolonged wait times were associated with increased the complications for patients receiving surgery for adolescent idiopathic scoliosis. Patients who waited longer than six months for surgery were more likely to need additional surgery and had increased odds of having an adverse event. These differences reflect increases in the sizes and stiffness of spinal curvatures with prolonged wait times. In terms of secondary outcomes, there were significantly higher percentages of both patients with a progression of curvature of more than $10^{\circ}$ and patients with prolonged surgery and less correction of the curvature (Table 2) among patients who waited longer than six months compared with those who waited less than six months.

Empirically derived maximal acceptable wait times have been determined for few surgical procedures. The Canadian Pediatric Surgical Wait Times Project has developed consensus-based access targets for more than 800 diagnoses in 11 surgical disciplines. For example, the consensus access target for infants with hernia was 21 days for infants aged less than 1 year. ${ }^{20} \mathrm{~A}$ subsequent empirically based target found that a waiting time longer than 14 days in young children was associated with a significant increase in the rate of incarceration. ${ }^{26}$ In this study, for the purposes of statistical analyses, we used six months as the access target based on expert consensus from the Canadian Pediatric Surgical Wait Times Project. Analysis of data revealed that three months (97 days) was the shortest wait time associated with sufficient progression of curvature to warrant additional surgery. Thus, a three-month maximal acceptable wait time could have eliminated the need for additional surgery. An ROC curve associated with adverse events also suggested wait times of three or four months as potential access targets. However, there is no potential gain and there are no cost savings associated with prolonging wait times to reduce false positives (i.e., using the four-month working target instead of the three-month target) (Figure 1).

Arguments could be made that not having to wait for surgery is optimal. However, there are disadvantages to wait times that are too short: patients may wish to bank blood, and the decision to have surgery is not one that can be taken lightly. Furthermore, increased resources would be needed to meet shorter access targets, leading to the potential for operating rooms to sit idle.

In summary, an access target of three months has the potential to eliminate additional surgery and reduce the risk of adverse events while providing sufficient time for surgical preparation. This study provides a second example of how the empirically derived maximal acceptable wait time is shorter than the consensus target. ${ }^{27}$

\section{Limitations}

This study was carried out retrospectively, so biases in chart and radiographic abstraction may have occurred. A prospective study would likely have minimized this bias. However, prospective studies would pose practical and ethical issues because patients who are informed of the hypothetical risks posed by long wait times could reasonably demand earlier surgery. We minimized the biases in chart and radiographic abstraction by abstracting patient chart details separately and blinding ourselves to the length of the wait time when obtaining radiographic data.

This study was done at a single institution. The Hospital for Sick Children is the largest children's hospital in Canada and the only pediatric hospital in Toronto. All sequential patients over a seven-year period received similar care and were given similar surgical techniques using segmental instrumentation. Because each patient who was seen and who consented for surgery

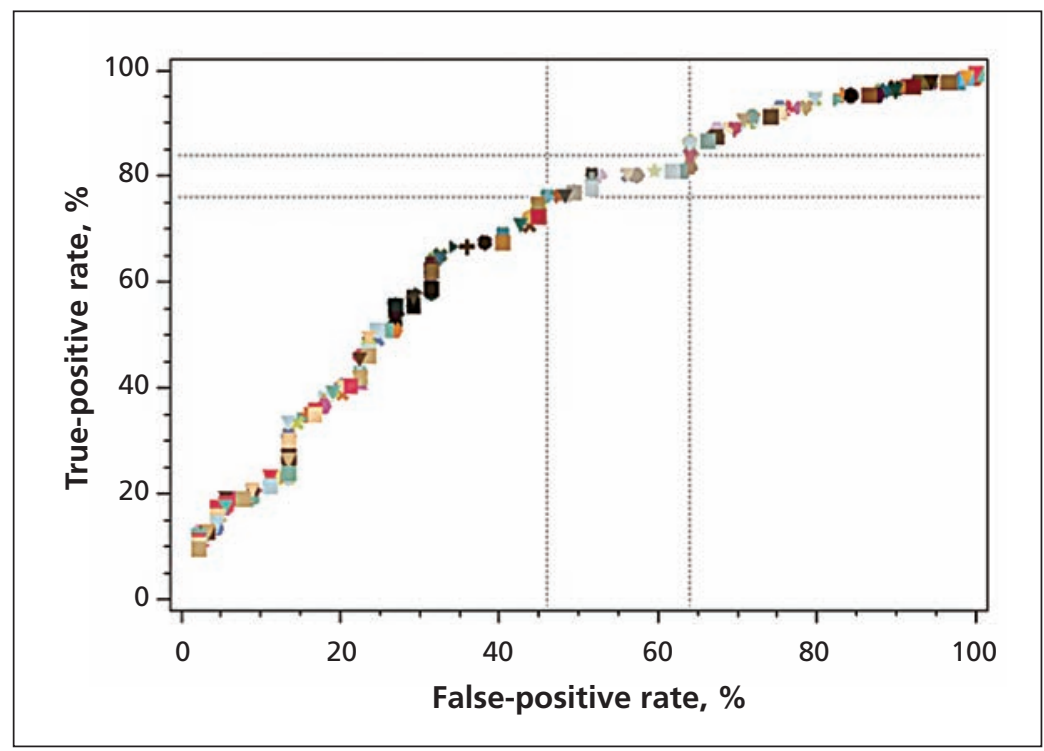

Figure 1: Receiver-operator characteristic (ROC) curve for adverse events related to surgical wait times. Each symbol represents a different cutoff wait time ranging from 1 to 365 days. True positives reflect instances of actual adverse events that may be prevented at a given cutoff value. False positives reflect instances of no adverse events that were thought to have been prevented at a given cutoff value. There is no clear inflection point on the curve. Two operating points are marked. The left operating point indicates a cutoff of four months (true-positive rate $=76 \%$, false-positive rate $=46 \%$ ); the right operating point indicates a cutoff of three months (true-positive rate $=84 \%$, false-positive rate $=64 \%$ ). 
had their procedures done by the same surgeon, surgeon bias was eliminated as a potential reason for a patient to require additional surgery.

The need for additional surgery may have been reduced by newer alternative techniques for correcting scoliosis that use only pedicle screws. However, it is possible that wait times of longer than six months resulted in increased risk of adverse events irrespective of the type of instrumentation as larger curvatures are more difficult to correct.

Finally, the reasons for waiting for surgery were not always clear. Generally, new patients were added to the end of the waiting list and were given surgery as openings became available. However, there are other potential reasons for prolonged waits, inlcuding surgeons being unavailable, families attempting to schedule surgery to coincide with school holidays and facilities having inadequate resources.

\section{Conclusion}

Prolonged wait times increase the probability of adverse events for the surgical treatment of adolescent idiopathic scoliosis. A maximal acceptable wait time based on minimizing the risk of additional surgery due to progression of curvature was three months, which is considerably less than the time frame originally determined by consensus opinion. The highest risks of adverse events due to prolonged wait times occurred in patients who were skeletally immature and had larger curvatures of the spine. Patients with these risks should be prioritized and monitored for progression of curvature while waiting for surgery. The ability to meet a three-month access target, on the national level, has resource implications, ${ }^{21}$ sufficient operating room time, personnel, bedspace and funding are necessary. Waiting to see a spinal specialist after receiving a referral from a family physician can add further delay. Referrals should therefore be prioritized and accompanied by Cobb angle measurements to help identify patients who are already candidates for surgery. A maximal acceptable wait time that leads to a reduction in the progression of curvature also has the potential to reduce the strain on healthcare resources by decreasing the need for additional surgery.

\section{References}

1. Smyrnis T, Antoniou D, Valavanis J, et al. Idiopathic scoliosis: characteristics and epidemiology. Orthopedics 1987;10:921-6.

2. Wong HK, Hui JH, Rajan U, et al. Idiopathic scoliosis in Singapore schoolchildren: a prevalence study 15 years into the screening program. Spine 2005;30:1188-96.

3. Yawn BP, Yawn RA, Hodge D, et al. A population-based study of school scoliosis screening. JAMA. 1999;282:1427-32.

4. Berry JG, Lieu TA, Forbes PW, et al. Hospital volumes for common pediatric specialty operations. Arch Pediatr Adolesc Med 2007; 161:38-43.
5. Kim YJ, Lenke LG, Kim J, et al. Comparative analysis of pedicle screw versus hybrid instrumentation in posterior spinal fusion of adolescent idiopathic scoliosis. Spine 2006;31:291-8.

6. Weinstein SL, Ponseti IV. Curve progression in idiopathic scoliosis. J Bone Joint Surg Am 1983;65:447-55.

7. Weinstein SL, Zavala DC, Ponseti IV. Idiopathic scoliosis: longterm follow-up and prognosis in untreated patients. J Bone Joint Surg Am 1981;63:702-12.

8. Suh PB, MacEwen GD. Idiopathic scoliosis in males. A natural history study. Spine 1988;13:1091-5.

9. Peterson LE, Nachemson AL. Prediction of progression of the curve in girls who have adolescent idiopathic scoliosis of moderate severity. Logistic regression analysis based on data from The Brace Study of the Scoliosis Research Society. J Bone Joint Surg Am 1995;77:823-7.

10. Ylikoski M. Growth and progression of adolescent idiopathic scoliosis in girls. J Pediatr Orthop B 2005;14:320-4.

11. Lonstein JE, Carlson JM. The prediction of curve progression in untreated idiopathic scoliosis during growth. J Bone Joint Surg Am 1984;66:1061-71.

12. Picault C, deMauroy JC, Mouilleseaux B, et al. Natural history of idiopathic scoliosis in girls and boys. Spine 1986;11:777-8.

13. Weinstein SL. Natural history. Spine 1999;24:2592-600.

14. Bunnell WP. The natural history of idiopathic scoliosis before skeletal maturity. Spine 1986;11:773-6.

15. Conner-Spady BL, Sanmugasunderam S, Courtright $P$, et al. Patient and physician perspectives of maximum acceptable waiting times for cataract surgery. Can J Ophthalmol 2005;40:439-47.

16. Ho E, Coyte PC, Bombardier C, et al. Ontario patients' acceptance of waiting times for knee replacements. J Rheumatol 1994;21:2101-5.

17. Kee F, McDonald P, Gaffney B. Prioritising the cardiac surgery waiting list: the angina patient's perspective. Heart 1997;77:330-2.

18. Miller GG. Waiting for an operation: parents' perspectives. Can J Surg 2004;47:179-81.

19. Rodrigue JR, Baz MA. Waiting for lung transplantation: quality of life, mood, caregiving strain and benefit, and social intimacy of spouses. Clin Transplant 2007;21:722-7.

20. National pediatric surgical wait times strategy: access targets. Ottawa (ON): Health Canada; 2007. Available: www.hc-sc.gc.ca /hcs-sss/pubs/system-regime/2006-wait-attente/ncyhc/index-eng. php (accessed 2010 Sep. 1)

21. Schaafsma J. Are there better ways to determine wait times? CMAJ 2006;174:1551-2.

22. Ontario wait times initiative Ottawa (ON): Ministry of Health and Long-term Care; 2007. Available: www.health.gov.on.ca/en/pro /programs/waittimes/surgery/data.aspx\#1 (accessed 2011 Apr. 4)

23. Delorme $\mathrm{S}$, Labelle $\mathrm{H}$, Aubin $\mathrm{CE}$. Is Cobb angle progression a good indicator in adolescent idiopathic scoliosis? Spine 2002;27: E145-51.

24. Escalada F, Marco E, Duarte E, et al. Growth and curve stabilization in girls with adolescent idiopathic scoliosis. Spine 2005; 30:411-7.

25. Soucacos PN, Zacharis K, Gelalis J, et al. Assessment of curve progression in idiopathic scoliosis. Eur Spine J 1998;7:270-7.

26. Zamakhshary M, To T, Guan J, et al. Risk of incarceration of inguinal hernia among infants and young children awaiting elective surgery. CMAJ 2008;179:1001-5.

27. Zamakhshary M, To T, Guan J, et al. Risk of incarceration of inguinal hernia among infants and young children awaiting elective surgery. CMAJ 2008;179:1001-5.

Affiliations: From St. Michael's Hospital (Ahn), University of Toronto Spine Program, University of Toronto, Toronto, Ont.; the Department of Surgery (Kreder. Mohamed, Wright), University of Toronto, Toronto, Ont.; Health Policy, Management and Evaluation (Ahn, Kreder, Mohamed, Beaton, Wright), Sunnybrook Health Sciences Centre, Toronto, Ont.; Sunnybrook Health Sciences Centre (Kreder), Toronto, Ont.; and the Department of Surgery (Wright), Hospital for Sick Children, Toronto, Ont.

Contributors: Henry Ahn was responsible for the collection of the data. Henry Ahn, Dorcas Beaton and James Wright were responsible for the analysis of the data. All of the authors were responsible for the design of the study, the interpretation of the results and the drafting of the manuscript. All of the authors approved the final version submitted for publication. 